\title{
Clinicohistopathological features of Fibroadenoma Breast in patients less than 20 years of age and its comparison with elder patients
}

\author{
Brijesh Thakur $^{1}$, Vatsala Misra ${ }^{2}$ \\ ${ }^{I}$ Department Of Pathology, SGRRIM\&HS, Dehrdun, India \\ ${ }^{2}$ Department Of Pathology, M.L.N. Medical College, Allahabad, India
}

\begin{abstract}
Fibroadenomas are the most common benign breast tumour in young women of 20-30 years of age. In last 5 years an increase in the incidence of breast lumps in females of less than 20 years has been observed. The present study has been done to evaluate the pattern of various clinicohistopathological parameters in younger age group in comparison to elder patients $(<20 \&>20$ yrs $) .188$ lumpectomy specimens of female patients, histologically diagnosed as fibroadenoma breast, were studied retrospectively for various clinichistopathological parameters (size, number, ipsilateral or bilateral, growth pattern, apocrine metaplasia, adenosis, fibrocystic changes, leaf like pattern, hyperplasia \& others). Patients were divided in two groups taking the 20 years as cut-off. All the findings were compared to find out any difference in young $(<20 y r s)$ and elder group $(>20$ yrs). There was increased incidence and frequency of changes like apocrine metaplasia, adenosis, leaf like pattern, stromal growth and myxoid changes in $<20$ yrs of females. However further larger studies are needed to know the exact etiology and pathogenesis of these changes.
\end{abstract}

Key Words: Fibroadenoma, adolescence, leaf like pattern, predictor

\section{Introduction:}

Fibroadenoma are the most common tumors clinically and pathologically in adolescent and women of child bearing age group; arising from the epithelium and stroma of the terminal duct-lobular unit of breast. ${ }^{[1]} \mathrm{An}$ estrogen dependency has been suggested for the growth of fibroadenomas. ${ }^{[2,3]}$ Mostly fibroadenomas present as a sharply demarcated, firm mass, usually not more than $3 \mathrm{~cm}$ in diameter. The cut surface is solid, grayish white, and bulging, with a whorl-like pattern and slit-like spaces. ${ }^{[4]}$ Fibroadenomas from women younger than 20 years of age tend to have more cellular stroma and more proliferative epithelium. ${ }^{[5]}$

Fibroadenoma and phyllodes tumor both share biphasic histomorphological pattern; however distinct histologic features, such as an increased heterogeneous stromal cellularity rendering its leaf-like architectural pattern, variable stromal cell atypia and increased mitosis favours the diagnosis of phyllodes tumor. ${ }^{[6,7]}$ Epithelial clefts or leaf like pattern can also occur in fibroadenomas due to stromal proliferation especially in adolescent age group. ${ }^{[1,8]}$

In the present study, we tried to evaluate the changing pattern of occurrence of fibroadenoma towards younger females along with comparison of frequency of various clinicohistopathological parameters or changes in two age groups $(<20 \&>20 \mathrm{yrs})$.

\section{Material and Methods:}

Lumpectomy specimens of 222 patients with clinical impression and gross features suggestive of fibroadenoma breast from year 2008 to 2011 were studied retrospectively from archives of the Department of Pathology. Out of these, 34 cases were histologically diagnosed as lesions other than fibroadenoma which included fibrocystic disease, tubular adenoma, intaductal papilloma, acute mastitis, phyllodes tumor and invasive ductal carcinoma (Table 1). Rest of the cases were histologically classified as fibroadenoma breast by paraffin embedded haematoxylin \& eosin stained slides $(188 / 222 ; 84.69 \%)$. All these cases included only female patients and were studied in detail.

In past few years we observed in our institute that there were major differences in occurrence of fibroadenoma and associated changes in diverse age groups especially regarding adolescent age group. So we divided these patients into two groups by using arbitrary line for age ( $<20 \&>20$ groups) and compared for various clinical (size, number, ipsilateral or bilateral presentation) and histological parameters including pattern of growth whether pericanalicular, intracanalicular or mixed; apocrine metaplasia, adenosis, epithelial hyperplasia, leaf like pattern, fibrocystic changes, stromal growth, atypical ductal hyperplasia and other changes like myxoid degeneration, hyalinization or fibrosis. The following criterias were used in the present series:

1. Phyllodes tumor was distinguished from fibroadenoma using Rosen's criteria, ie, expansion and increased cellularity of the stromal component with often a leaf-like stromal growth pattern. ${ }^{11]}$ 
2. Fibroadenomas were classified as pericanalicular or intracanalicular when $90 \%$ of the tumor displayed that particular type of growth pattern. If neither type could be assigned to a tumor, we diagnosed it as mixed histologic type. ${ }^{[9]}$

3. Leaf-like pattern (enhanced intracanalicular pattern) characterized by the projection of cellular stroma into clefts of cystic spaces. ${ }^{[1]}$

4. Stromal overgrowth was defined as the presence of stroma without epithelium in any low-power field $(\times 40) .^{[10]}$

5. Epithelial hyperplasia, if present, was categorized as usual type or atypical ductal hyperplasia according to the World Health Organization 2003 criteria. ${ }^{[6]}$

Both lesions show similar histological features, with the benign phyllodes tumor showing an accentuated intracanalicular appearance, leafy fronds accompanied by stromal hypercellularity often with periepithelial stromal hypercellularity. Fibroadenoma has none, few or poorly formed fronds and generally no significant stromal hypercellularity. In benign cases with histological ambiguity, the WHO Working Group recommends favouring a diagnosis of fibroadenoma or using the descriptive term 'benign fibroepithelial neoplasm, ${ }^{[11]}$

\section{Statistics:}

The Pearson chi-square test with or without Yates' correction was used to study the difference in various clinicohistopathological parameters in the two groups using DAG stat for computation. $P$ values $<.05$ were regarded as significant.

\section{Results:}

These 188 cases clinically and histologically diagnosed as fibroadenona breast were analysed for the frequency of occurrence of fibroadenoma in various age groups of female patients. The mean age of patients was 22.5 years (range, $11-50$ years). Out of these, 102 (54.26\%) cases were in younger age group (11 - 20 yrs, mean $17.5 \mathrm{yrs})$ and $86(45.74 \%)$ in other one $(>20 \mathrm{yrs}$, mean $27.5 \mathrm{yrs})$.

In 23 patients (12.23\%) multiple tumors were found; out of which $65.22 \%$ cases $(15 / 23)$ were in younger females $(11-20 \mathrm{yrs})$. In young patients with multiple tumors, $60 \%(9 / 15)$ of the patients had fibroadenomas located in both breasts which was significantly higher than the bilateral fibroadenomas observed in elder females $(\mathrm{P}<.05)$.

Lumpectomy specimens showed varying range of size $(0.5-16 \mathrm{~cm})$. Fibroadenoma of maximum diameter $(16 \mathrm{~cm}$.) was found in younger age group however mean diameter was $3.8 \mathrm{~cm}$; no significant difference from mean diameter $(3.65 \mathrm{~cm}$.) in $>20$ yrs of age was found.

The frequencies of various histopathologic changes observed in the sections of fibroadenomas are shown in Table 2. Of these fibroadenomas, predominant pattern of growth was mixed histologic type in both age groups; $87.26 \%$ (89/102 in <20yrs) and $88.37 \%$ (76/86 in $>20 \mathrm{yrs})$. Pericanalicular pattern was noticed in $2.94 \%$ cases $(3 / 102)$ and $2.33 \%$ cases $(2 / 86)$ while intracanalicular in $9.8 \%$ cases $(10 / 102)$ and $9.3 \%$ cases $(8 / 86)$ in both age groups respectively. No significant difference was observed.

In this series, apocrine metaplasia (18.63\%), adenosis $(9.80 \%)$ and stromal overgrowth $(3.92 \%)$ within fibroadenomas were more common in younger females but did not show significant difference from elder age group $(17.44 \%, 6.98 \%$ \& $1.16 \%$ respectively). Leaf like pattern due to overt intracanalicular pattern was seen in $12.75 \%(13 / 102)$ of adolescent patients in contrast to $6.98 \%$ (6/86) of others. The youngest age of this type of changes within fibroadenoma was 14 yrs in this study. Fibrocystic changes were more frequent in cases more than 20 yrs of age group (significant, $\mathrm{P}<.05$ ).

$6.98 \%$ older females $(6 / 86)$ showed epithelial hyperplasia in comparison to $0.98 \%(1 / 102)$ in young ones (significant, $\mathrm{P}<.05$ ). Other changes like atypical ductal hyperplasia, myxoid degeneration, hyalinization, calcification, fibrosis showed no significant difference in both the groups. No case with atypical ductal hyperplasia was found in younger females in this study. No heterologus element like cartilage was identified in any of the cases from the two groups.

\section{Discussion:}

The basic characteristic feature of all fibroadenomas is proliferation of glandular as well as stromal elements with a sharply defined border and the pericanalicular or intracanalicular or mixed growth pattern. The enhanced intracanalicular pattern of some fibroadenomas bears a superficial resemblance to the clefted architecture of benign Phyllodes tumor and occasionally the distinction between the two tumor types may be difficult. ${ }^{[1,4]}$ In such cases WHO recommends favours the diagnosis of fibroadenoma in order to avoid over treatment. Overall recurrence rate of both are comparable suggesting similar outcome. ${ }^{[11]}$ 
Fibroadenomas with sclerosing adenosis, papillary apocrine hyperplasia, cysts, or epithelial calcifications have been designated as "complex". ${ }^{[12]}$ Fibroadenomas can occur in women of any age, but the peak incidence is during the second and third decades of life. ${ }^{[1,9,13]}$ However some studies show rising rate in second decade. ${ }^{[14,15,16]}$ Also in the present series $54.26 \%$ cases were under 20 yrs of age alomg with predominant growth pattern of mixed histologic type.

Fibroadenoma are stimulated by estrogen and progesterone, pregnancy, and lactation, and they undergo atrophic changes in menopause. ${ }^{[14,16,17]}$ This increasing rate of early presentation of fibroadenoma may be due to early or increased exposure to estrogen, changing life style. Exogenous hormone or hormonal imbalance; intake or oral contraceptive use may be underlying basic etiology. A number of factors are thought to increase chances of developing a fibroadenoma which include dark-skinned race, high socioeconomic status, low body mass index (BMI), no or low number of full-term pregnancies. ${ }^{[18]}$ However, few studies show that higher intake of fruits and vegetables, higher number of live births, use of oral contraceptives and moderate exercise are associated with lower frequency of fibroadenomas. ${ }^{[19]}$

Multiple breast fibroadenomas were found to be more common in younger patients in the present series; however showed no significant difference as compared to elder patients. Few studies found increased incidence of multiple tumors in teenagers and late adolescence. ${ }^{[20,21]}$ Unlike women with a single fibroadenoma, most of the patients with multiple fibroadenomas have a strong family history of these tumors. ${ }^{[22]}$ Bilateral multiple fibroadenomas showed significant difference between both age groups in the study. Increased risk of recurrence after excision has been suggested in case of multiple tumors especially in young ones. ${ }^{[21]}$

The incidence of apocrine metaplasia and adenosis inside fibroadenoma has been reported to be $14 \%$ and $6 \%$, respectively. ${ }^{[23]}$ This study showed some higher values as compared to these analysis; even more in $<20$ yrs of age. Fibrocystic changes within fibroadenomas showed preponderance towards elder age group similar to an earlier study. ${ }^{[9]}$ Leaf like pattern was present more frequently in younger females as compared to the elder ones; however difference was not significant. Some studies described these changes ${ }^{[9,24]}$ but the data for these changes are scarce. The pathology, incidence and course of these focal phyllodes tumor like feature yet to be ascertained.

Epithelial hyperplasia within fibroadenoma was seen more frequently in elder patients in this series; however it can be found at all ages. Frequencies of both usual ductal and atypical hyperplasia in younger females patients were lower in our study than those found by Dupont et al. ${ }^{[12]}$

This study was an attempt to explore large variety of clinicohistological features of fibroadenomas, some of which are expected to be of importance in context of management of patient. These changes may act as predictors for the outcome of the patients. Currently there are no known identifiable characteristics to predict their unanticipated behaviour or recurrence especially in younger patients so that we can avoid the aggressive treatment or proper follow up can be instituted. However, multi-institutional and larger studies should be planned for further validation.

Table 1: Histological diagnosis of 222 patients, originally with clinical and gross impression of fibroadenoma

\begin{tabular}{|l|c|}
\hline Histological diagnosis & No. (\%) of Cases \\
\hline Fibroadenoma & $188(84.69)$ \\
Fibrocystic Disease & $23(10.36)$ \\
Tubular adenoma & $03(1.35)$ \\
Intraductal Papilloma & $01(0.45)$ \\
Phyllodes Tumor & $02(0.90)$ \\
Acute Mastitis & $01(0.45)$ \\
Pseudoangiomatous Stromal Hyperplasia & $01(0.45)$ \\
Invasive Ductal Carcinoma & $03(1.35)$ \\
\hline
\end{tabular}


Clinicohistopathological features of Fibroadenoma Breast in patients less than 20 years of age ....

Table 2: Comparative chart of various clinicohistopathological parameters in 188 cases diagnosed as Fibroadenoma

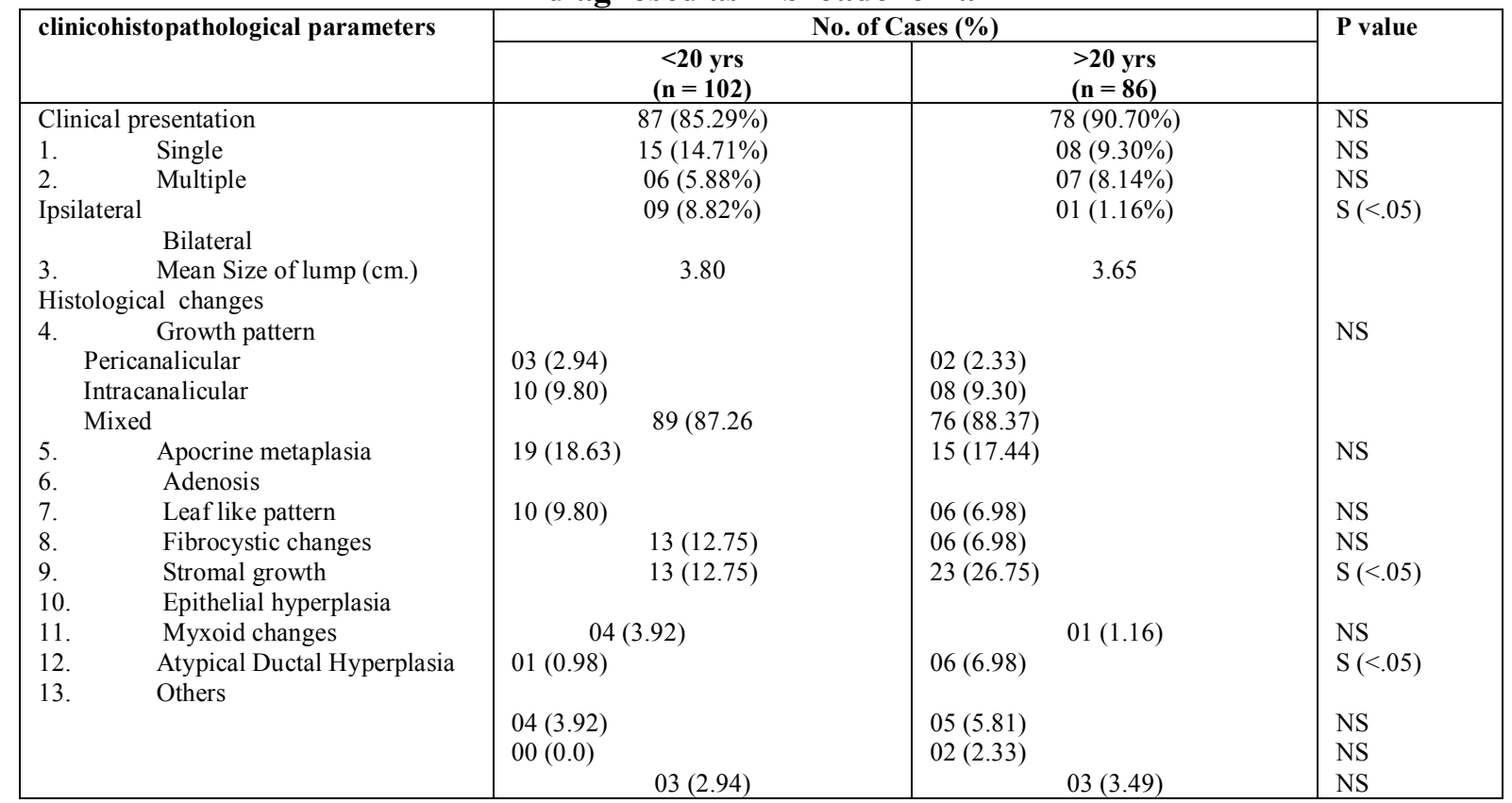

(NS- nonsignificant, S- significant)

Figure: 1.

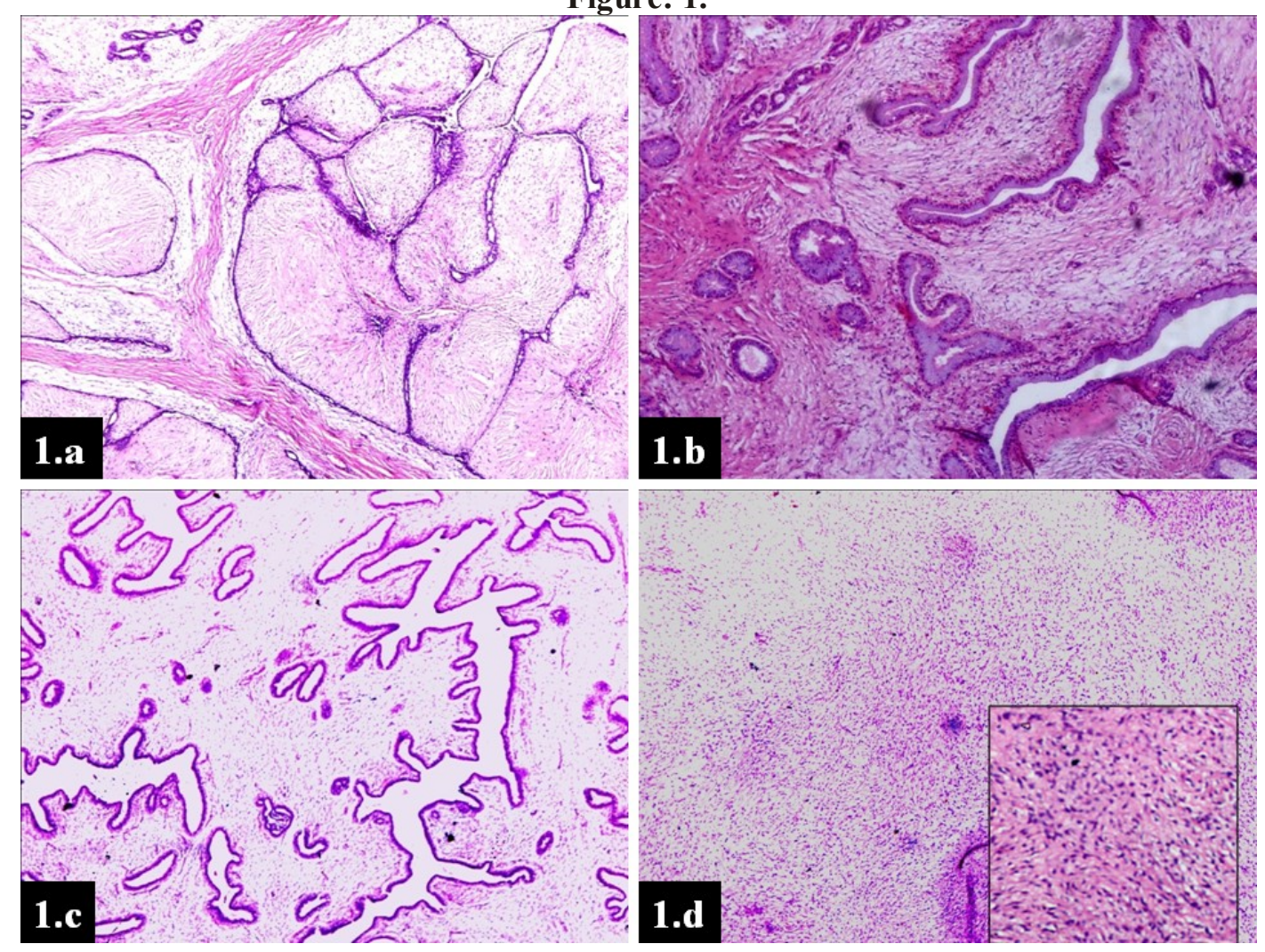




\section{References:}

[1]. Rosen PP. Fibroepithelial Neoplasms. In Rosen PP. Rosen's Breast Pathology, $3^{\text {rd }}$ edition. Lippincott Williams and Wilkins 2009:187-229

[2]. Bundred NJ. Aetiological factors in benign breast disease. Br J Surg 1994;81:788-9.

[3]. Sapino A, Bosco M, Cassoni P, Castellano I, Arisio R, Cserni G, et al. Estrogen receptor-beta is expressed in stromal cells of fibroadenoma and phyllodes tumors of the breast. Mod Pathology 2006;19:599-606.

[4]. Rosai J. Breast. In Rosai and Ackerman's Surgical Pathology, Vol 2, 10th Edition. Michael Houston 2011: p.1665

[5]. Kasami M, Vnencak-Jones CL, Manning S, Dupont WD, Jensen RA, Page DL. Monoclonality in fibroadenomas with complex histology and phyllodal features. Breast Cancer Res Treat. 1998;50:185-191.

[6]. Tavassoli FA, Devilee P, editors. World Health Organization Classification of Tumors. Pathogenesis and Genetics of Tumors of the Breast and Female Genital Tract. IARC Press: Lyon 2003.

[7]. Tan PH, Jayabaskar T, Chuah KL, Lee HY, Tan Y, Hilmy M, et al. Phyllodes tumors of the breast. The role of pathologic parameters. Am J Clin Pathol. 2005;123:529-540.

[8]. Chung EM, Cube R, Hall GJ, González C., Stocker JT, Glassman LM. Breast Masses in Children and Adolescents: RadiologicPathologic Correlation. RadioGraphics. 2009;29:907-931.

[9]. Kuijper A, Mommers EC, van der Wall E, van Diest PJ. Histopathology of fibroadenoma of the breast. Am J Clin Pathol. 2001;115:736-742

[10]. Ward RM, Evans HL. Cystosarcoma phyllodes: a clinicopathologic study of 26 cases. Cancer. 1986;58:2282-2289.

[11]. Tan PH, Ellis IO. Myoepithelial and epithelial-myoepithelial, mesenchymal and fibroepithelial breast lesions: updates from the WHO Classification of Tumours of the Breast 2012. J Clin Pathol. 2013; 66: 465-470.

[12]. Dupont WD, Page DL, Parl FF, Vnencak-Jones CL, Plummer WD, Rados MS et al. Long-term risk of breast cancer in women with fibroadenoma. N Engl J Med. 1994;331:10-15.

[13]. Foster ME, Garrahan N, Williams S. Fibroadenoma of the breast. J R Coll Surg Edinb. 1988;33:16-19.

[14]. Greenberg R, Skornick Y, Kaplan O. Management of breast fibroadenomas. J Gen Intern Med. 1998;13:640-645

[15]. Jayasinghe Y, Patricia SS. Fibroadenomas in adolescence Current Opinion in Obstetrics \& Gynecology. 2009; 21: 5: 402-406

[16]. Levy MS, Sella T, Alweiss T, Craciun I, Libson E, Mally B. Incidence and Management of Complex Fibroadenomas. American J of Roentgenology. 2008;190: 1:214-218

[17]. Abu-Rahmeh Z, Nseir W, Naroditzky I. Invasive ductal carcinoma within fibroadenoma and lung metastases. Int J Gen Med. 2012; 5: 19-21.

[18]. http://www.localhealth.com/article/fibroadenoma/causes

[19]. Nelson ZC, Ray RM, Wu C, Stalsberg H, Porter P, Lampe JW et al. Fruit and Vegetable Intakes Are Associated with Lower Risk of Breast Fibroadenomas in Chinese Women. Journal of Nutrition. 2010;140:1294-1301.

[20]. Williamson ME, Lyons K, Hughes LE. Multiple fibroadenomas of the breast: a problem of uncertain incidence and management. Ann R Coll Surg Engl. 1993;75:161-163

[21]. Morris A, Shaffer K. Recurrent bilateral giant fibroadenomas of the breasts. Radiology Case Reports. 2007;2:96.

[22]. Cale Beuglet C, Soriano RZ, Kurtz AB, Goldberg BB. Fibroadenoma of the breast sonomammography correlated with pathology in 122 patients. AJR. 1983;140:369-75.

[23]. Azzopardi JG. Fibroadenoma. In: Bennington JL, ed. Problems in Breast Pathology. Philadelphia, PA: Saunders; 1979:39-56.

[24]. Jacobs TW, Chen YY, Guinee DG Jr, Holden JA, Cha I, Bauermeister DE et al. Fibroepithelial lesions with cellular stroma on breast core needle biopsy: are there predictors of outcome on surgical excision? Am J Clin Pathol. 2005;124:342-54

\section{Legends to figure:}

\section{Figure: 1.}

a. Fibroadenoma showing intracanalicular pattern ( H \& E X100)

b. Fibroadenoma showing pericanalicular pattern (H \& E X100)

c. Fibroadenoma showing leaf like pattern (H \& E X100)

d. Fibroadenoma showing prominent stromal growth (H \& E X40). Inset shows higher magnification (H \& E $\mathrm{X} 400)$. 